Ethiopian Journal of Environmental Studies \& Management 8(Suppl. 1): 752 - 758, 2015.

ISSN:1998-0507

doi: http://dx.doi.org/10.4314/ejesm.v8i1.2S

Submitted: September 11, 2014

Accepted: September 15, 2015

\title{
TELECOMMUNICATIONS' USAGE AND PUBLIC TRANSPORT PASSENGERS' TRAVEL BEHAVIOUR IN LAGOS, NIGERIA AGUNLOYE, 0.0.
}

Department of Urban and Regional Planning, University of Lagos, Akoka, Yaba, Lagos State, Nigeria

Email: oagunloye@unilag.edu.ng

\begin{abstract}
This study investigated the nature and magnitude of effects of mobile phone usage on interurban public transport passengers' travels in Lagos metropolis. A set of structured questionnaire were administered on 1,483 early morning (6am-8am) inter-urban public transport passengers of the selected 76 inter-urban motor parks of Lagos metropolis. Using multi-stage sampling technique, zones of survey, inter-urban motor parks, vehicle types and occupancy ratio were identified and an average of 7, 14 and 43 passengers were interviewed at each of low, medium and high inter-urban motor parks based on passengers' flow on a Wednesday, Friday and Saturday mornings. Data were analysed using frequency tables and ANOVA. The study estimated the average inter-urban cancelled as 1 trip as there was a statistical significant variation in inter-urban cancelled trips of passengers in Lagos metropolis using one way ANOVA ( $F=8.168, p>0.05)$. There was a statistical significant variation in inter-urban cancelled trips of passengers in Lagos metropolis using one way ANOVA (F=14.734, p>0.05). This paper captured urban prosperity, low carbon city regeneration, smart growth and low cost transportation as the socio-economic relevance of the study.
\end{abstract}

Key Words: Mobile Telecommunication, Inter Urban, Public Transport, Travels

\section{Introduction}

Communications networks make society a reality (Akwule, 2002). Prior to the invention of telephone, all forms of communications in the city were dependent on physical interactions and written correspondence. Movement was on foot, horse, river and horse driven trolley. This required very close proximity for urban dwellers, often limited to a distance of three to five kilometres (Akwule, 2002). As a result, land use in the city was dependent on the type of commerce located in a neighbourhood. Each city had separate clusters for hatters, furriers, financiers bankers, and advocates, among others. Business was conducted on foot, requiring personal contact to obtain orders, negotiate deals and to meet prospective clients. As these quarters became congested, businessmen would pay higher costs to obtain a central location in close proximity to clients and suppliers. As a result of the invention of telephone, contact with clients and suppliers became easier. The net effect of the telephone was a reduction in the frequency of trips while the distance of the trips increased and; because movement by foot and horse was no longer time efficient, alternative transportation means were required. Telephone relieved congestion in the cities, but it in turn, created a market for a new form of transportation (Akwule, 2002). It 
was this complementary effect that expanded and transformed the urban form.

Zumkeller (2000) used empirical platform and modelling to study the impact of telecommunications and transport on spatial behaviour and found a combined platform of physical and virtual off-home activities. Handy (2001) studied travel choices in Berkeley and found that, the road mode of transportation was mostly used because of its travel frequency; Fujiwara, (2005) examined the Urban travel behaviour characteristics of 13 cities based on household interview survey in East Asia and found statistical significant variations between and within the cities' phone calls usage and call distances, number of received calls, travel time, travel frequency, number of inter-urban calls, distance of received calls and callers' durations as telecommunications attributes; Obalowo (2007), investigated the impacts of telecommunication on households' travel demand in Yaba, Lagos and found that there were lesser demands for households travels due to mobile phones usages; Fadare and Salami (2004) empirically analyzed the impact of pre GSM fixed land line telephone uses and travel behaviour of residents in Oshogbo and found that, there were statistical positive significant relationships between trip purpose, distance of calls and travel outcomes.

Telecommunication has not only for the sender but also for the addressee of both mobile and immobile elements (Zumkeller, 1997). The immobile element can be understood as the fact not to be forced to move physically whereas the mobile element applies both to the sender and the addressee since the communicated information extends their spatial action field. Thus the only distinction between sender and addressee is the question whether the one or the other was active or passive (Zumkeller, 1997). When we try to translate this concept to physical transport we start to understand why the passive element of transport (to be visited) is much less important than the active element (to move), since the associated cost in terms of time, money, energy etc. is much higher for the active part (Zumkeller, 1997). Nevertheless, we have to state that the passive part of transport contributes to the extension of the spatial action field of the visited person in the same way as telecommunication does. These very basic definitions indicate a strong interrelation between transport and telecommunication both contributing in a more or less complementary manner to the (neverending?) extension of spatial behaviour of humans (Zumkeller, 1997). First quantitative but descriptive results concerning the interrelationship between physical and virtual transport (telecommunication) become possible by expanding our observation of spatial behaviour patterns by including the dimension of overcoming space on a virtual level (Zumkeller, 1997).

The results of this empirical approach have clearly indicated that the interrelationship goes far beyond what is currently understood and incorporated in our general understanding. A basic phenomenon, however, has already emerged: there is a further increase to be expected in the field of telecommunication as well as in the field of transport giving the background of increasing spatial division of labour and further dispersion and specialization of private life.

However, this will happen consistently, interrelated between transport and communication, probably with a stronger growth in the fields of telecommunication due to the lower cost in terms of personal time, cost, pollution etc. And since it has been shown that evidently there is little hope for substitution theories and hopes for decreasing transport volumes it can be assumed that human positive curiosity is the driving factor for the demand to extend 
spatial action fields as much as possible if not restricted by personal intellectual, time and cost budgets or social and environmental limitations (Zumkeller, 1997). Agunloye (2013) also found in his study of Mobile Phone Usage and Travel Behaviour of Airline Passengers in Lagos, Nigeria that airline passengers travel more as they use mobile phone, which is a case of tele-induction. Similar cases are as follows:

\section{Substitution versus Complementarities}

The certainly interesting question of mutual interdependences between transport and telecommunication cannot be answered finally based on results of already completed surveys. The most eminent role of telecommunication as a tool to plan and perform physical transport became visible as well as the option to perform trips more efficiently. This can be associated with the substitution of more or less standardized trips. But, on the other hand, telecommunication opens the window to get in contact with far away destinations possibly resulting in a related long-distance travel. This view is consistent with the historical fact that transport and development of media were more or less correlated (Zumkeller, 2000).

\section{Modelling Substitution-the Seoul Case}

As part of a comprehensive research a modeling approach was implemented in Seoul, for which results can be reported here. This approach was based on integrated transport/telecommunication surveys and interactive interviews performed in banks (telebanking) and storehouses (teleshopping). The resulting transition probabilities (reduced by the share of interviewers having had already experience, were applied to the Transport and Telecommunication Activity Pattern by a Monte-Carlo-Simulation process (Lee and McNally, 2003). Thus, it was possible to define certain rules for the impacts of the substitution of an activity on the subsequent activities. After aggregation, the potentials to substitute trip could be quantified for the metropolitan area of Seoul as well as on the level of the infrastructure (Lee and McNally, 2003). It is on this basis that this paper intends to investigate the extent of nature and magnitude of effects of mobile phone usage on inter-urban public transport passengers' travels in Lagos, Nigeria.

\section{Methodology}

Data on nature and magnitude of effects of mobile phone usage on interurban public transport passengers' travels in Lagos, Nigeria were sourced from questionnaire administration. The sample frame of the study was 8,021 early morning (6am-8am) inter-urban public transport passengers of the selected 76 inter-urban motor parks of Lagos metropolis while the sample size translated to $(20.5 \%)$ based on Cochran's sample size formula. However, the successfully completed and returned questionnaires that were used for the analysis was $18.5 \%$ (1,483 questionnaires) for the final analysis of the study. The content and construct validity of measurement were used. The multi-stage sampling technique was used for the study The sampling procedure for this study firstly encompassed the identification of the zones of survey, secondly, identification of the entire interurban motor parks in each of the zones. Thirdly, identification of average number of vehicles in each carrying capacity (low 76 vehicles; medium 99 vehicles and high 121 vehicles) generating the aforementioned average number of early morning inter-urban passengers. Finally, an average of 7,14 and 43 passengers were interviewed at each of low, medium and high inter-urban motor parks on Wednesday, Friday and Saturday mornings. The choice of these days was in accordance with the works of Olaseni (2010). The reliability of instrument used was confirmed by Cronbach's Alpha 
reliability statistical tool, using the Split Half Method. Frequency tables and ANOVA were used for data analyses through the SPSS data analyses software programme.

\section{Results and Discussion}

A problem of high rate of accidents involving large number of human lives annually can be reduced if the movement flow is substituted by mobile phone usages as communication flow is a form of spatial interaction. Although Salomon (1986) remarked that the choice of mode of interaction either through transportation or communications depends on which mode better serve the ends. The variables of nature and magnitude of effects of mobile phone usage covers number of cancelled inter-urban travels, number of inter-urban travels and number of accompanied inter urban trips. One-Way ANOVA was used to analyse the significant variations between nature and magnitude of effects continuous variables and inter-urban mobility in the study area. Results also test the formulated Hypothesis that "There are no significant relationships between interurban mobile phones usages and conventional effects (complimentarity, reduction and induction) of mobile phones usages in the study area'. The analysis further disaggregates into the various inter- urban motor parks (high, medium and low) in Lagos metropolis for the purpose of precision. The grouping of inter-urban passengers into low, medium and high classes represents inter-urban motor parks with $<50,51-100$ and $>100$ early morning passengers respectively. This classification justifies the variance in passengers' flow from each of the inter-urban motor parks of Lagos metropolis as it also help to present a comprehensive and logical analysis of inter-urban travellers in each class of the entire study area.

\section{Inter Urban Cancelled Trips in the past 1 month}

Results in Table 1 revealed that respondents' inter-urban cancelled trips in motor parks were none $(38.8 \%),<2$ trips (34.5\%), 3-4 trips (20.9\%), 5-6 (3.7\%) and $>6$ trips $(2.1 \%)$ in Lagos metropolis. The study estimated the average inter-urban cancelled as 1 trip. The study also revealed that, there is a statistical significant variation in inter-urban cancelled trips of passengers in Lagos metropolis using one way ANOVA $(\mathrm{F}=8.168, \mathrm{p}>0.05)$ (see table 2). This result also reject the null hypothesis that "there is no significant relationship between inter-urban mobile phones usages and conventional effect (reduction in inter-urban travels) of mobile phones usages in the study area" and accepts the alternative hypothesis.

Table 1: Inter Urban Cancelled Trips in the past 1 month

\begin{tabular}{lllllllll}
\hline Cancelled Trips & \multicolumn{2}{l}{$\begin{array}{l}\text { High Capacity } \\
\text { Motor Parks }\end{array}$} & \multicolumn{2}{l}{$\begin{array}{l}\text { Medium Capacity } \\
\text { Motor Parks }\end{array}$} & \multicolumn{2}{l}{$\begin{array}{l}\text { Low Capacity } \\
\text { Motor Parks }\end{array}$} & \multicolumn{2}{l}{ Totals } \\
& Freq. & percent & Freq. & percent & Freq. & percent & Freq. & $\%$ \\
\hline none & 299 & 32.9 & 161 & 45.6 & 115 & 52.0 & 575 & 38.8 \\
$<2$ & 345 & 38.0 & 97 & 27.5 & 70 & 31.7 & 512 & 34.5 \\
$3-4$ & 223 & 24.5 & 61 & 17.3 & 26 & 11.8 & 310 & 20.9 \\
$5-6$ & 31 & 3.4 & 18 & 5.1 & 6 & 2.7 & 55 & 3.7 \\
above 6 & 11 & 1.2 & 16 & 4.5 & 4 & 1.8 & 31 & 2.1 \\
Totals & 909 & 100 & 353 & 100 & 221 & 100 & 1,483 & 100 \\
\hline
\end{tabular}


Table 2: ANOVA, Testing Variance in Respondents' Inter Urban Cancelled Trips in Lagos metropolis

\begin{tabular}{llllll}
\hline & $\begin{array}{l}\text { Sum of } \\
\text { Squares }\end{array}$ & df & Mean Square & F & Sig. \\
\hline Between & 44.396 & 6 & 7.399 & 8.168 & .000 \\
Groups & 1337.012 & 1476 & .906 & & \\
$\begin{array}{l}\text { Within Groups } \\
\text { Total }\end{array}$ & 1381.408 & 1482 & & & \\
\hline
\end{tabular}

Passengers' Inter Urban Travels Made Because of Phone Calls in the past 1 month

As shown in table 3, respondents' inter-urban travels made because of phone calls in motor parks were none $(33.6 \%),<2$ trips $(40.3 \%), 3-4$ trips $(19.6 \%), 5-6$ $(2.8 \%)$ and $>6$ trips $(3.7 \%)$ in Lagos metropolis. The study estimated the average inter-urban travels made because of phone calls as 1.5. The study also revealed that, there is a statistical significant variation in inter-urban cancelled trips of passengers in Lagos metropolis using one way ANOVA $(\mathrm{F}=14.734, \mathrm{p}>0.05)$ (see table 4). This result also reject the null hypothesis that "there is no significant relationship between inter-urban mobile phones usages and conventional effect (inductions in inter-urban mobility) of mobile phones usages in the study area" and accepts the alternative hypothesis.

Table 3: Passengers' Inter Urban Travels Made Because of Phone Calls in the past 1 month

\begin{tabular}{|c|c|c|c|c|c|c|c|c|}
\hline \multirow{2}{*}{$\begin{array}{l}\text { Number of } \\
\text { Travels Made } \\
\text { Because of Phone } \\
\text { Calls }\end{array}$} & \multicolumn{2}{|c|}{$\begin{array}{l}\text { High Capacity } \\
\text { Motor Parks }\end{array}$} & \multicolumn{2}{|c|}{$\begin{array}{l}\text { Medium Capacity } \\
\text { Motor Parks }\end{array}$} & \multicolumn{2}{|c|}{$\begin{array}{l}\text { Low Capacity } \\
\text { Motor Parks }\end{array}$} & \multicolumn{2}{|l|}{ Totals } \\
\hline & Freq. & percent & Freq. & percent & Freq. & percent & Freq. & $\%$ \\
\hline none & 299 & 32.9 & 111 & 31.4 & 88 & 39.8 & 498 & 33.6 \\
\hline$<2$ & 395 & 43.5 & 117 & 33.1 & 85 & 38.5 & 597 & 40.3 \\
\hline $3-4$ & 182 & 20.0 & 78 & 22.1 & 32 & 14.5 & 292 & 19.6 \\
\hline $5-6$ & 25 & 2.8 & 12 & 3.4 & 4 & 1.8 & 41 & 2.8 \\
\hline above 6 & 8 & 0.9 & 35 & 9.9 & 12 & 5.4 & 55 & 3.7 \\
\hline Totals & 909 & 100 & 353 & 100 & 221 & 100 & 1,483 & 100 \\
\hline
\end{tabular}

Table 4: ANOVA, Testing Variance in Respondents' Inter Urban Travels Made Because of Phone Calls in Lagos metropolis

\begin{tabular}{llllll}
\hline & $\begin{array}{l}\text { Sum of } \\
\text { Squares }\end{array}$ & df & Mean Square & F & Sig. \\
\hline Between & 81.820 & 6 & 13.637 & 14.734 & .000 \\
Groups & 6 & & & \\
Within Groups & 1366.047 & 1476 & .926 & & \\
Total & 1447.866 & 1482 & & & \\
\hline
\end{tabular}

\section{Passengers' Inter-Urban Complemented Travels in the past 1 month}

Results showed in table 5, that respondents' inter-urban complemented travels in motor parks were none $(31.0 \%)$,
$<2$ trips $(32.8 \%), 3-4$ trips $(22.6 \%), 5-6$ $(6.3 \%)$ and $>6$ trips $(7.3 \%)$ in Lagos metropolis. The study estimated the average inter-urban complemented travels as 1.6 trips. The study also revealed that, 
there is a statistical significant variation in inter-urban complemented travels of passengers in Lagos metropolis using one way ANOVA ( $\mathrm{F}=14.641, \mathrm{p}>0.05)$ (see table 6). This result also reject the null hypothesis that "there is no significant relationship between inter-urban mobile phones usages and respondents' travels complementarity of inter-urban passengers in the study area" thereby accepts the alternative hypothesis.

Table 5: Passengers' Inter-Urban Complemented travels in the past 1 month

\begin{tabular}{|c|c|c|c|c|c|c|c|c|}
\hline \multirow{3}{*}{$\begin{array}{l}\text { Complemented } \\
\text { Travels Because } \\
\text { of Phone Calls }\end{array}$} & High & Capacity & \multirow{2}{*}{\multicolumn{2}{|c|}{$\begin{array}{l}\text { Medium Capacity } \\
\text { Motor Parks }\end{array}$}} & Low & Capacity & Totals & \\
\hline & \multicolumn{2}{|c|}{ Motor Parks } & & & \multicolumn{4}{|c|}{ Motor Parks } \\
\hline & Freq. & percent & Freq. & percent & Freq. & percent & Freq. & $\%$ \\
\hline none & 299 & 32.9 & 84 & 23.8 & 76 & 34.4 & 459 & 31.0 \\
\hline$<2$ & 308 & 33.9 & 106 & 30.0 & 72 & 32.6 & 486 & 32.8 \\
\hline $3-4$ & 209 & 23.0 & 89 & 25.2 & 37 & 16.7 & 335 & 22.6 \\
\hline $5-6$ & 54 & 5.9 & 29 & 8.2 & 11 & 5.0 & 94 & 6.3 \\
\hline above 6 & 39 & 4.3 & 45 & 12.7 & 25 & 11.3 & 109 & 7.3 \\
\hline Totals & 909 & 100 & 353 & 100 & 221 & 100 & 1,483 & 100 \\
\hline
\end{tabular}

Table 6: ANOVA, Testing Variance in Respondents' Inter-Urban Complemented Travels in Lagos metropolis

\begin{tabular}{llllll}
\hline & \multicolumn{2}{l}{ Sum of } & & & \\
& Squares & df & Mean Square & F & Sig. \\
\hline Between & 115.038 & 6 & 19.173 & 14.641 & .000 \\
Groups & 1932.873 & 1476 & 1.310 & & \\
Within Groups & 1947.911 & 1482 & & & \\
Total & 2047.92 & & \\
\hline
\end{tabular}

\section{Recommendations}

Based on the results of nature and magnitude of effects of mobile phones usage (phone calls) on inter-urban travel behaviour, this study recommends that, the service providers should improve their services through their marketing department as they increase their coverage areas so as to encourage the use of mobile phones with a view to reducing road traffic congestion and accidents. This could also be achieved by the reductions in services' costs by the various services providers. Since it has been established that the challenge of high rate of accidents involving large number of human lives annually can be reduced if the movement flow is substituted for mobile phones usages as communication flow is a form of spatial interaction, the use of mobile phone calls is suggested for substitution for human movement. This can also be achieved through corporate policies of organizations in Nigeria in line with the present Nigeria communication commission code for corporate operators.

\section{Conclusion}

This study has investigated the nature and magnitude of effects of mobile phone usage on inter-urban public transport passengers' travels in Lagos metropolis and found the estimation of average interurban cancelled as 1 trip as there was a statistical significant variation in interurban cancelled trips of passengers in Lagos metropolis using one way ANOVA $(\mathrm{F}=8.168, \mathrm{p}>0.05)$. The study estimated the average inter-urban travels made because of phone calls as 1.5 as there was a 
statistical significant variation in interurban cancelled trips of passengers in Lagos metropolis using one way ANOVA $(\mathrm{F}=14.734, \mathrm{p}>0.05)$. also, estimated the average inter-urban complemented travels was 1.6 trips while there was a statistical significant variation in inter-urban complemented travels of passengers in Lagos metropolis using one way ANOVA $(\mathrm{F}=14.641, \mathrm{p}>0.05)$. It has also validated the theory of tele-substitution and proved to have potentials for solving challenges of road traffic accidents and congestion. This study has implications on wealth creations, travels demands modelling and forecasting, climate change adaptability, low carbon city generation, smart growth creation among others.

\section{References}

Agunloye, O.O. (2013). Mobile Phone Usage and Travel Behaviour of Airline Passengers in Lagos, Nigeria Journal of Engineering and Environmental Studies, 4(1): 33-40.

Akwule, R.U. (2002). Telecommunications in Nigeria. Journal of Communications, 15(3):21-44.

Fadare, S.O. and Salami, B.T. (2004). Impact of pre GSM fixed Line Telephone Uses and Travel Behaviour of Residents in Oshogbo, Nigeria: Journal of Transport Geography, 12 (2): 159-164.

Handy, S. (2001). Travel choices in berkley: Automobiles, Accessibility, and the Evolution of road mode, Berkeley Planning Journal, 20(3): 15-33.

Lee, M.S. and McNally, M.G. (2003). On the structure of weekly activity / travel patterns. Transportation Research Part A: Policy and Practice, 37(10): 823-839.

Obalowo, A.O. (2007). Impacts of mobile telecommunication on household travel demand. A case study of Lagos State Development Property Corporation Residential Estate Adekunle, Yaba. B.Sc. Dissertation. Department of Urban and Regional Planning, University of Lagos, Akoka, Yaba, Lagos.

Olaseni, A.M. (2010). Locational Analysis of Intercity Road Passengers' Terminals in Lagos. Ph.D. Thesis. Department of Geography and Regional Planning, Olabisi Onabanjo University, Ago-Iwoye.

Salomon, I. (1986). Telecommunications and travel: substitution or modified mobility? Journal of Transport Economics and Policy, 19(3): 219-235.

Zumkeller, D. (2000). The impact of telecommunications and transport on spatial behaviour. Periodica polytechnica ser Transport Engineer, 28(1-2): 23-38. 